\title{
TREINAMENTO \& DESENVOLVIMENTO NA EDUCAÇÃO A DISTÂNCIA
}

\author{
Edivandro Luiz Tecchio - Universidade Federal de Santa Catarina - \\ edivandro@gmail.com \\ Marcos Baptista Lopez Dalmau - Universidade Federal de Santa Catarina - \\ dalmau@ cse.ufsc.br \\ Thiago Soares Nunes - Universidade Federal de Santa Catarina - \\ adm.thiagosn@gmail.com \\ Humberto Tonani Tosta - Universidade Federal de Santa Catarina - \\ humtosta@gmail.com
}

\begin{abstract}
RESUMO
Programas de T\&D que desenvolvam competências são necessários para obter um desempenho elevado, já que este é o balizador das ações organizacionais. Nesse sentido, o objetivo deste estudo é identificar as competências necessárias para a proposição de um programa de T\&D para os tutores do Curso de Administração na Modalidade a Distância da UFSC. A pesquisa caracterizou-se como: estudo de caso, exploratório, descritivo, documental, bibliográfico e predominantemente qualitativo. $\mathrm{O}$ cargo tutor passou por um redesenho, assim, para o desempenho das atividades o tutor deve possuir diversas competências, como, por exemplo: organização e planejamento, pró-atividade, automotivação, flexibilidade, comprometimento, liderança, e outras. Por fim, criou-se um programa de T\&D com base na identificação das competências exigidas pelo cargo.
\end{abstract}

Palavras-chaves: Treinamento e Desenvolvimento. Competências. Educação a Distância. Tutor.

\section{TRAINING AND DEVELOPMENT IN DISTANCE EDUCATION}

\begin{abstract}
$T \& D$ programs that develop competences are necessary for the obtaining of a high acting, since this is the marked of the actions in the organizational extent. The objective of this study to identify the competencies required for the proposition of a T\&D program for tutors of the Management Course in distance education modality of the UFSC. The methodology was characterized as: case study, exploratory, descriptive, documental, bibliographical, applied and predominantly qualitative. The position tutor passed for a redraw, like this, for the acting of the activities the tutor should possess several competences: organization and planning, for-activity, solemnity-motivation, flexibility, compromising, leadership, and others. Finally, was created a T\&D program based on the identification of the competencies required for the position.
\end{abstract}

Keywords: Training and Development. Competences. Distance Education. Tutor.

\section{INTRODUÇÃO}

Nos últimos anos as organizações conscientes de que seu sucesso é determinado pelas habilidades, aptidões, talentos e experiências de seus empregados, passaram a atribuir maior relevância à gestão de pessoas, principalmente no que diz respeito ao desenvolvimento de competências, ou seja, desenvolvimento do conjunto de conhecimentos, habilidades e atitudes inter-relacionadas necessárias à consecução de determinado trabalho (Brandão; Guimarães, 2001). Dessa maneira, torna-se necessário 
oferecer à força de trabalho oportunidades de formação contínua, atualização, treinamento e desenvolvimento visando à obtenção de um desempenho superior por parte da organização (Belloni, 2001).

O processo de treinamento e desenvolvimento de pessoas surge como opção para atualização da força de trabalho e para o desenvolvimento de competências necessárias à consecução dos objetivos organizacionais. Em programas de Educação a Distância (EaD), a exemplo do que ocorre nas organizações, torna-se necessário que os atores envolvidos com o processo possuam uma ampla quantidade de competências para que os objetivos do curso sejam alcançados, portanto, deve-se elaborar programas de treinamento e desenvolvimento que atendam tal demanda. No processo de $\mathrm{EaD}$ um ator que merece especial atenção é o tutor. No Curso de Graduação em Administração na Modalidade a Distância da Universidade Federal de Santa Catarina - presente nos estados de Roraima, Bahia, Paraná, Santa Catarina e Rio Grande do Sul - isto não é diferente, tendo em vista que, (Malvestiti, 2005), a tutoria é uma necessidade dos sistemas de educação a distância, principalmente porque a existência de contato humano é uma exigência do processo de ensino-aprendizagem.

O referido curso, para auxiliar os alunos dispõe de um sistema de tutoria, composto entre outros profissionais, por aproximadamente 40 tutores, responsáveis por fazerem a intermediação do conhecimento entre o professor e o aluno, acompanhar os alunos no decorrer do curso, avaliá-los e fornecer feedback às suas possíveis dúvidas, tornando-se assim, responsável direto pelo desempenho de seus tutorados. Torna-se necessário, dessa maneira, ter tutores com alto nível de competências e altamente capacitados para corresponderem às expectativas dos alunos.

Mediante o contexto apresentado, identificar as competências necessárias para a proposição de um programa de treinamento e desenvolvimento para os tutores do Curso de Administração na Modalidade a Distância da Universidade Federal de Santa Catarina, constitui-se no objetivo deste artigo.

\section{TREINAMENTO E DESENVOLVIMENTO (T\&D)}

Treinamento e desenvolvimento pode ser definido como um processo de educação, onde os empregados são convidados a desenvolver competências que proporcionem seu desenvolvimento profissional, possibilitando-o assumir novas posições dentro da organização e realizar um trabalho com desempenho superior. $O$ processo de treinamento geralmente é iniciado após a definição dos objetivos de educação profissional, sendo composto, por quatro etapas: levantamento das necessidades de treinamento, planejamento e programação, execução dos programas e avaliação, além do feedback, importante em todas as etapas do processo de treinamento (Marras, 2000; Hanashiro et al., 2008; Gil, 2007).

O levantamento das necessidades de treinamento deve levar em consideração três categorias de análise: a organização, a tarefa e os recursos humanos (Tachizawa et al., 2006). A análise organizacional possibilita à organização identificar como ocorre seu crescimento, a que se deve e quais os fatores que o dificultam, permitindo, ainda, identificar qual o nível de contribuição dos recursos humanos no alcance dos objetivos organizacionais (Gil, 1994). $\mathrm{Na}$ análise das tarefas identificam-se quais são suas atividades componentes, além de elencar quais conhecimentos, habilidades e atitudes são necessários para a execução do trabalho (Gil, 1994). A análise dos recursos humanos consiste em verificar se as pessoas são adequadas às necessidades da organização. Realizada a análise organizacional e a análise da tarefa, identifica-se o potencial de crescimento de cada indivíduo e possíveis problemas de desempenho que 
possam ser corrigidos por meio do treinamento (Tachizawa et al., 2006). Uma boa identificação das necessidades faz com que o treinamento atenda aos objetivos da organização. Isto faz com que se evite o risco desta incorrer em custos desnecessários e, em cursos que não trazem proveito, nem para a organização nem para o empregado, já que ela irá nortear todo o processo de treinamento.

$\mathrm{Na}$ etapa de planejamento e programação do treinamento, objetiva-se verificar quais mudanças organizacionais são almejadas e qual o nível de desempenho deve-se alcançar por meio do treinamento. Para tanto, deve-se ter sempre em mente quais objetivos serão satisfeitos com o treinamento. Nessa etapa deve-se definir métodos e mídias instrucionais, descrever e sequenciar o conteúdo, buscar exemplos, exercícios e atividades, para que, de posse dessas informações, se possa criar o material instrucional. Além disso, a organização deve certificar-se de que todos os materiais se complementam, estão escritos de forma clara e combinam em um treinamento unificado e direcionado para os objetivos de aprendizagem determinados, sob pena de que,se isso não for levado em consideração, o treinamento pode ser um fracasso, a organização somente incorrer em custos, além da frustração dos treinandos quanto ao treinamento (Dessler, 2003).

$\mathrm{Na}$ etapa de execução dos programas de treinamento este é posto em prática. $\mathrm{O}$ processo de execução do treinamento é essencial, é nesta etapa que se verifica a viabilidade de todo o planejamento realizado. O planejamento é o norteador da execução, porém, requer uma série de providências, uma vez que, nem sempre o planejamento quando executado é percebido como adequado (Hanashiro et al., 2008). $\mathrm{Na}$ execução realizam-se, também, as adaptações necessárias conforme a reação observada dos treinandos. Na etapa de execução reside a última oportunidade para o alcance dos objetivos traçados. Aqui, o professor/instrutor assume um papel de extrema importância, ele é o diferencial e o elemento crucial para o sucesso ou fracasso na medida em que ele é responsável por criar um ambiente propício ao aprendizado durante as sessões do treinamento.

A avaliação dos resultados do treinamento é a última etapa do processo de treinamento. Ela tem por finalidade aferir os resultados conseguidos, mediante comparação com o que foi planejado pela organização (Marras, 2000). Assim sendo, pode-se definir avaliação como "qualquer tentativa no sentido de obter informações sobre os efeitos de um programa de treinamento e para determinar o valor do treinamento à luz dessas informações" (Hamblin citado por Gil, 1994, p. 78). Ela pode ocorrer por meio de diversas categorias de análise, (Hanashiro et al., 2008; Marras, 2000). No entanto, para fins deste estudo serão consideradas as categorias de avaliação propostas por Gil (1994). Assim, têm-se como categorias de avaliação: as reações dos empregados, a aprendizagem, o comportamento no cargo e o resultado obtido.

\section{GESTÃO POR COMPETÊNCIAS}

O processo de gestão por competências tem seu início na identificação do gap de competências da organização, ou seja, estabelece-se a lacuna entre as competências internas disponíveis na organização e as competências necessárias para o alcance dos objetivos previamente traçados, segundo a intenção estratégica da empresa (Brandão; Guimarães, 2001). Os demais passos compreendem o planejamento, captação, desenvolvimento e avaliação de competências. Dessa maneira, competência diz respeito ao conjunto de conhecimentos, habilidades e atitudes interdependentes e necessárias à consecução de determinado propósito. Em complemento, Leme (2005) expõe que os 
conhecimentos, as habilidades e as atitudes são os pilares das competências. Segundo o autor, o conhecimento é o saber, a habilidade é o saber fazer e a atitude é o querer fazer.

Dutra (2004) classifica as competências em organizacionais e individuais. As competências organizacionais decorrem do processo de desenvolvimento da organização, concretizando-se em seu patrimônio de conhecimentos, determinando as vantagens competitivas da mesma. Já as competências individuais, podem ser definidas como uma ação que implica mobilizar, integrar, transferir conhecimentos, recursos, habilidades, que agreguem valor econômico à organização e valor social ao indivíduo. Há uma relação íntima entre competências individuais e organizacionais, uma vez que, entre organização e indivíduo existe uma troca contínua de competências. Assim, o estabelecimento de competências individuais deve estar ligado às competências organizacionais, pois há uma influência mútua entre elas.

\section{TUTORIA EM EDUCAÇÃO A DISTÂNCIA (EaD)}

É essencial às instituições que promovem cursos a distância dispor de órgãos específicos para acompanhamento, atendimento e apoio aos alunos, proporcionandolhes a aquisição de hábitos e técnicas de estudo, interação com tutores e com outros alunos, afim de, motivá-los a permanecer no processo de ensino-aprendizagem (Landim, 1997). "A tutoria é uma necessidade dos sistemas de educação a distância, principalmente porque a existência de contato humano é uma exigência do processo ensino-aprendizagem" (Gomes citado por Malvestiti, 2005, p. 3). O apoio ao aluno é primordial na educação a distância. Dentro do sistema de apoio, algumas funções são fundamentais como o apoio ao desenvolvimento pessoal, motivação e estímulo ao aluno, sendo estas, funções do tutor. Para Emerenciano et al. (2001) o tutor é sempre alguém que possui duas características essenciais: domínio do conteúdo técnicocientífico e, ao mesmo tempo, habilidade para estimular a busca de respostas pelo participante.

As tarefas básicas e imprescindíveis que um tutor deverá desempenhar podem ser unidas em três grandes grupos: orientação, que se refere a uma orientação continuada ao aluno; acadêmica, onde o tutor exerce um papel de facilitador de aprendizagem; e institucional e de conexão, que diz respeito à ligação que o mesmo estabelece entre alunos e instituições e as de caráter institucional e burocrático. O tutor deve possuir algumas qualidades, como: autenticidade, maturidade emocional, capacidade empática, inteligência e agilidade mental, capacidade de escutar, cultura social, estabilidade emocional, liderança, entre outras (Aretio, 2002). Portanto, "o grande desafio do processo de tutoria é como construir e manter uma interação que realmente suporte a aprendizagem", pois, as grandes questões com as quais as instituições de educação a distância se deparam, no que se refere às estruturas de suporte e tutoria, estão relacionadas com a "construção de um ambiente adequado, tempo de dedicação dos tutores, promoção de uma relação empática e informal entre alunos e tutores" (Moraes, 2004, p. 105).

\section{MÉTODO}

A pesquisa caracterizou-se como sendo um estudo exploratório, pois, buscou-se integrar práticas de recursos humanos, como é o caso do treinamento e desenvolvimento de pessoal, com o sistema de educação a distância. A pesquisa também é classificada como descritiva, uma vez que foram descritas quais as atividades devem ser desenvolvidas pelo tutor, bem como quais as competências necessárias para que ocorra 
um bom desempenho por parte do mesmo e que deverão ser desenvolvidas, caso estejam ausentes. Com relação aos procedimentos técnicos utilizados, conforme Triviños (2006), o presente estudo caracteriza-se como estudo de caso, pois aprofundase na realidade de um caso em particular. Analisa-se apenas a tutoria do curso de Graduação em Administração a Distância, com o intuito de obter informações pertinentes que permitam a solução de um problema restrito, no caso a falta de um processo de treinamento e desenvolvimento de tutores que atenda a realidade do curso em questão. Cabe ressaltar que a pesquisa caracteriza-se ainda como sendo predominantemente qualitativa. Conforme Triviños (2006), uma das características da pesquisa qualitativa é a atuação do pesquisador no meio onde a pesquisa se desenvolve, o que fica caracterizado por serem os pesquisadores participantes do projeto onde a pesquisa foi desenvolvida.

Em relação aos sujeitos de pesquisa, a mesma foi composta por três Tutores Supervisores e pelo Coordenador da Tutoria. Entende-se que estas pessoas, por serem de nível de supervisão e coordenação, influenciam diretamente o desempenho dos tutores, bem como possuem amplo conhecimento a respeito das competências necessárias para o desenvolvimento do trabalho de tutoria. Em relação à fonte de dados secundários, foi realizada uma pesquisa documental, utilizando-se principalmente $\mathrm{o}$ projeto pedagógico do curso, artigos e pesquisas na área. Além disso, foi aplicado um formulário ("Gosto" - "Não Gosto" - "O Ideal Seria") aos Tutores Supervisores, onde os mesmos elencaram as competências que consideram necessárias ao tutor. Ainda para coleta de dados primários, foi realizada entrevista com o Coordenador da Tutoria. Por fim, com os dados coletados passou-se a descrevê-los. Por ser uma pesquisa predominantemente qualitativa, os dados obtidos foram descritos pelos autores e validados pela Coordenação de Tutoria, evitando que fossem expostos apenas com base na percepção dos autores.

\section{APRESENTAÇÃo E ANÁLISE DOS DADOS}

Conforme seu projeto pedagógico, para o desenvolvimento do Curso estabeleceuse uma rede de comunicação que possibilita o acompanhamento por parte dos professores, tutores e coordenação do desempenho e desenvolvimento de cada aluno, fazendo com que o aluno receba um retorno individualizado sobre seu desempenho, além de orientações e troca de informações complementares relativas aos conteúdos abordados em exercícios desenvolvidos. Para o acompanhamento da aprendizagem dos estudantes o curso conta com tutores e tutores-supervisores. Os tutores supervisores trabalham diretamente com os tutores, auxiliando nas atividades de rotina, fornecendo feedback sobre o desenvolvimento do curso. Os tutores têm relevante papel no Curso de Graduação em Administração a Distância, pois, atuam como elo entre os estudantes e a instituição. Cumprem o papel de facilitadores da aprendizagem, esclarecendo dúvidas, coletando informações sobre os estudantes para a equipe e, principalmente, na motivação dos alunos. Conforme exposto na fundamentação teórica, o tutor é responsável por auxiliar o aluno a sanar suas dúvidas, bem como fornecer-lhes orientações. Os contatos são realizados por e-mail, ambiente virtual de ensinoaprendizagem, chat e telefone.

Ao analisar as atividades desempenhadas pelos tutores do Curso de Graduação em Administração a Distância, percebeu-se que o cargo tutor é restrito em relação ao que a literatura especializada apresenta a respeito das atividades que o ocupante do cargo deve desempenhar, principalmente, se for considerado o exposto por Aretio (2002). Assim, faz-se necessário uma reformulação do desenho do cargo tutor, no que tange ao 


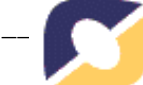

conteúdo do cargo. Esta ampliação do cargo ocorre de forma horizontal, ou seja, adicionam-se novas responsabilidades de mesmo nível. Nesse sentido, o cargo tutor passa a contemplar as seguintes atividades conforme quadro a seguir.

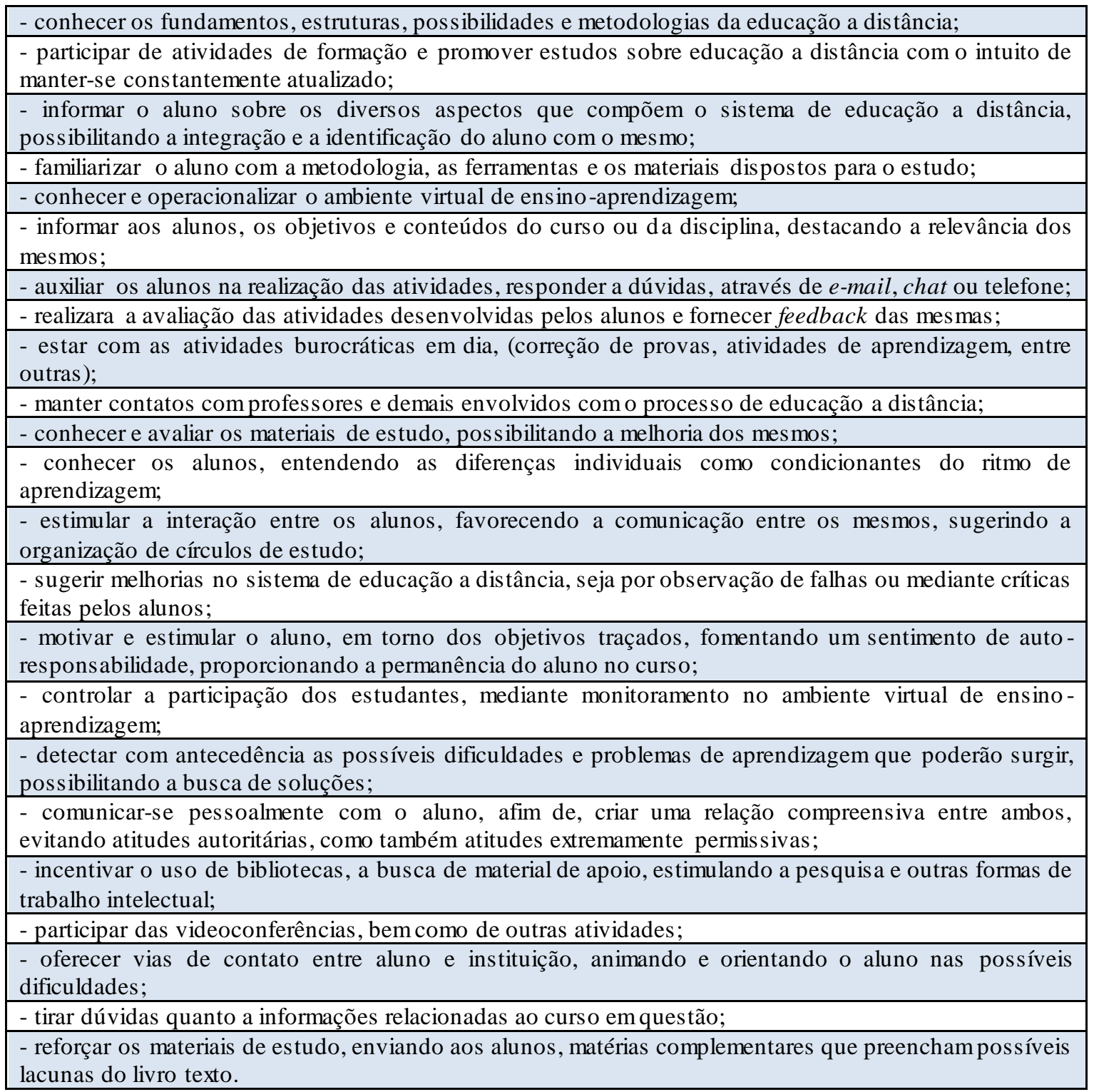

\section{Quadro 1: Atividades contempladas no cargo de Tutor}

Houve uma ampliação significativa do cargo, principalmente no que tange ao que é exposto no projeto pedagógico do curso. Diversas atividades foram inseridas, possibilitando a identificação e inclusão no perfil do cargo de diversas competências que antes não eram abarcadas pelo conteúdo que o cargo possuía. Partindo-se das atividades desempenhadas pelo tutor e das respostas obtidas com a aplicação do formulário ("Gosto" - "Não Gosto" - "O Ideal Seria") aos tutores-supervisores, pode-se elencar quais as competências que o tutor deve possuir para ocupar o cargo. Obtêm-se com isso, subsídios para definir qual o perfil do cargo. $\mathrm{O}$ perfil do cargo foi definido levando-se em consideração o conjunto de conhecimentos, habilidades e atitudes que o mesmo exige, ou seja, as competências que o cargo requer.

Para facilitar o desenvolvimento e a enumeração de indicadores de competências, classificaram-se as competências em comportamentais e técnicas. As competências comportamentais (atitudes) elencadas foram: organização e planejamento, pró- 
atividade, automotivação, capacidade de síntese e análise, empatia, equilibrio emocional, flexibilidade, assiduidade, comprometimento, liderança e criatividade. Já as competências técnicas (conhecimentos e habilidades) definidas foram: conhecimento das rotinas de trabalho, conhecimento em informática básica/ambiente virtual de ensinoaprendizagem, conhecimento sobre educação a distância/sobre o curso, relacionamentos interpessoais, comunicação (oral/escrita) e trabalho em equipe. Com o objetivo do curso elencado anteriormente, o perfil do cargo definido, as competências exigidas devidamente elencadas e com os indicadores definidos, conforme instrumento de levantamento de necessidades, chega-se ao final do processo de mapeamento de competências exigidas pelo cargo tutor. Conforme exposto por Rabaglio (2004) o mapeamento de competências oferece subsídios para todo o processo de gestão por competências. Assim sendo, será exposto o processo de treinamento e desenvolvimento definido para os tutores.

\subsection{O processo de Treinamento e Desenvolvimento na Tutoria}

O processo de treinamento e desenvolvimento proposto para a tutoria do Curso em questão está baseado no conceito de gestão por competências exposto quando da fundamentação teórica. O mesmo tem como objetivo alinhar a lacuna entre o nível de competência desejado e o nível real de competência possuído por cada tutor, com o intuito de atingir os objetivos determinados para o Curso. Não obstante, serão apresentadas todas as etapas do processo de treinamento definido para os tutores.

O levantamento das necessidades de treinamento, definido, neste caso específico, como avaliação do nível de competência de cada tutor, será realizado de forma cíclica, durante o semestre letivo. Ele será feito pelas seguintes pessoas: tutores supervisores, alunos, colegas tutores e o próprio tutor. O mesmo possui instrumento próprio (apêndice 1) elaborado a partir da definição dos indicadores de competências. Este instrumento está baseado no medidor de competências proposto por Rabaglio (2004). O instrumento de avaliação do nível de competência do tutor é composto por blocos, contendo a competência a ser avaliada, com seu respectivo conceito e seus indicadores. Cada indicador será caracterizado em uma escala de 1 a 5 , onde o 5 representa uma evidência muito forte do indicador em questão, sendo classificado como excelente, o 4 corresponde a um indício significativo do indicador, o qual significa bom, o 3 tem caráter mediano, ou seja, existe alguma evidência do indicador, o 2 significa insatisfatório e corresponde a pouca evidência do indicador investigado, por fim, o 1 representa a total ausência de evidência do indicador em questão, tanto que tem como significado inaceitável. Isto posto, passa-se expor o instrumento que será utilizado para mensuração do nível de competências dos tutores e identificação das necessidades de treinamento. A ficha de avaliação a ser preenchida (Apêndice 1) abrange todas as competências abordadas anteriormente e seus respectivos indicadores.

Para facilitar o cálculo e a compreensão, adotou-se peso 1 (um) para todos os indicadores de competência existentes no instrumento de avaliação. Após terem sido preenchidos os formulários de avaliação, deve-se fazer o cálculo do nível de competência. Sugere-se que o mesmo seja feito pela coordenação do curso. Para cada competência constante no instrumento de avaliação, deverá ser feito o somatório de todos os seus indicadores e dividir o total pelo número de indicadores da competência em questão. Após isso, deve-se somar esse índice ao índice da competência seguinte e assim, sucessivamente. Ao final divide-se o somatório dos índices de cada competência, pelo total de competências constantes nos instrumentos, obtendo-se o índice final de cada avaliado. Com relação aos resultados obtidos nesta avaliação considera-se como 
nível de competência regular, índices acima de 6,0 e bom acima de 8,0, valores abaixo desses, são considerados como refletindo um nível de competência ruim, ou seja, os tutores devem realizar os treinamentos com o intuito de alinhar as competências ao nível desejado. Portanto, com o instrumento de levantamento de necessidade definido e estruturado, chega-se ao final da primeira etapa do processo de treinamento. Dessa maneira, passa-se a etapa seguinte, o planejamento do processo de T\&D.

Após determinadas às necessidades de treinamento deve-se conceber um ambiente propício ao aprendizado. Deve-se deixar claro qual o intuito do treinamento e motivar o treinando para que ele esteja de prontidão para a realização de treinamento. Nesse sentido, quando do planejamento do treinamento deve-se estabelecer como será realizada a sensibilização dos treinandos. Sugere-se que essa sensibilização seja efetuada por meio de um feedback positivo em relação aos resultados obtidos na medição de competências, removendo obstáculos à aprendizagem e deixando clara a importância do desenvolvimento das competências para o bom andamento do Curso e atingimento dos objetivos deste, bem como dos objetivos pessoais de cada tutor. Outro ponto importante que deve-se deixar claro quando do planejamento do treinamento, referem-se às técnicas que serão usadas para a realização do treinamento e o tipo de treinamento que será desenvolvido. Sugere-se que, primeiramente, sejam usadas experiências positivas na realização do trabalho por parte de alguns tutores, para o treinamento dos demais. Diversos tutores adotam maneiras diferentes de desenvolverem as atividades relativas às rotinas de trabalho e algumas dessas experiências fazem com que determinada atividade seja realizada de forma mais efetiva. Essas atividades que refletem uma possibilidade de melhoria nos processos de tutoria devem ser repassadas a todos os demais. O treinamento assumirá, assim, a forma de treinamento no próprio local de trabalho.

Outra forma de treinamento a ser utilizada é a realização de workshops, onde os tutores elaboram artigos e apresentações, englobando assuntos relacionados às competências necessárias ou desejáveis ao tutor elencadas anteriormente. Isso é necessário, pois os mesmos podem ficar cientes da importância do conhecimento das peculiaridades da educação a distância, por exemplo, para a realização das atividades de tutoria. A realização de palestras é outra técnica a ser utilizada. Deve-se realizar palestras com pessoas externas e internas a organização e que tenham amplo conhecimento a respeito do tema a ser abordado, e também, das competências fundamentais ao tutor do Curso em questão. O desenvolvimento de manuais para a realização das atividades e rotinas da tutoria é outra estratégia e merece destaque. Os manuais são de grande importância para o treinamento, tanto de novos tutores, quanto dos tutores em atividade, além de servir como fonte permanente de consulta. Por fim, acredita-se que essas três técnicas, treinamento no local de trabalho, workshops e realização de palestras são adequadas à realidade do curso e devem ser implementadas. Desta forma, passa-se a explicitar como deve ser a execução do treinamento.

A execução do programa de treinamento deve ocorrer de forma constante, principalmente após o levantamento das necessidades de treinamento, onde estarão salientes as competências que deverão ser desenvolvidas. Nesse treinamento, os tutores com mais experiência e que conseguiram soluções efetivas para problemas e rotinas de trabalho, demonstram aos demais como o trabalho deve ser realizado, buscando com isso, um melhor desempenho nas atividades realizadas pelos tutores. Já os workshops serão realizados durante o expediente de trabalho, ou também em finais de semana. Sugere-se que seja realizado um workshop a cada dois meses. Com esta iniciativa, criase um clima de cooperação entre os colegas de trabalhos, uma vez que todos deverão se aprofundar nos temas relacionados às competências elencadas anteriormente, 
apresentando-os aos demais. Em paralelo aos workshops ocorrerão palestras com pessoas que possuem profundo conhecimento a respeito dos temas relacionados às rotinas de trabalho, à EAD e demais temas pertinentes ao ambiente de tutoria de um curso a distância. Serão realizadas em finais de semana, o chamado "falando com o mestre", já que os expositores são pessoas com expressivo conhecimento a respeito do tema a ser abordado. O uso do material impresso, conforme já exposto, restringe-se aos manuais contendo as rotinas e demais informações pertinentes e necessárias ao bom andamento das atividades, tornando-se fonte permanente de consulta, podendo ser usado sempre que o tutor estiver com dúvida em relação a alguma rotina ou procedimento de trabalho. Assim, todas as técnicas definidas no planejamento serão executadas, bastando, somente, fazer a avaliação dos resultados do treinamento.

$\mathrm{Na}$ fase de avaliação dos resultados é verificado se o treinamento realmente surtiu efeito e se de fato os treinandos assimilaram os conhecimentos a eles passados. Essa avaliação deverá ser realizada utilizando-se o mesmo instrumento para levantamento das necessidades de treinamento, ou seja, deverá ser realizada uma nova medição do nível de competência de cada tutor, comparando-se com o anterior. Isso possibilita verificar se o treinamento alcançou os resultados esperados e o tutor alinhou as competências deficitárias ao nível desejado. Além disso, essa avaliação fornece subsídios para a realização de novos treinamentos, tornando o processo de treinamento constante. Chega-se, dessa forma, ao final do processo de treinamento proposto para a tutoria do Curso de Graduação em Administração, modalidade a distância. Ele está baseado no conceito de gestão por competências e é composto, conforme pode ser observado, pelas quatro etapas elencadas pela literatura especializada: levantamento das necessidades, planejamento, execução e avaliação do treinamento.

\section{CONSIDERAÇÕES FINAIS}

Para o curso de Graduação em Administração na modalidade a Distância se faz necessária a criação de um sistema de treinamento e desenvolvimento que reflita a real necessidade de treinamento, bem como ofereça subsídios para que essas necessidades sejam sanadas. Para tanto, primeiramente, identificou-se qual o objetivo do curso. Após esta etapa foi feita uma análise do cargo tutor, identificou-se quais as competências necessárias e desejáveis ao tutor no desenvolvimento de suas atividades, bem como quais os indicadores a serem considerados para cada competência. Por fim, estruturouse um programa de treinamento e desenvolvimento baseado em competências. Com relação ao cargo tutor, percebeu-se que o cargo exposto no projeto pedagógico do curso é restrito quando comparado à teoria, principalmente com o exposto por Aretio (2002). O cargo foi redesenhado, sendo acrescentadas outras atividades de nível horizontal, portanto, houve um enriquecimento horizontal do cargo.

Já as competências identificadas como desejáveis e necessárias, foram classificadas em dois grupos: comportamentais e técnicas. Para cada competência foram identificados diversos indicadores, os quais servem de subsídio para mensurar o nível de competência possuído pelo tutor. Foram identificados ao total 97 indicadores que representam as competências mencionadas, e como pode ser observado no instrumento de levantamento de necessidades. Com relação ao processo de T\&D desenvolvido, o mesmo está baseado nas competências exigidas pelo cargo tutor. Para o treinamento dos tutores, utilizar-se-á o chamado treinamento no local de trabalho, workshops, palestras e material impresso - manuais contendo informações sobre rotinas e procedimentos de trabalho. A execução do treinamento ocorrerá durante a realização do trabalho ou em finais de semana, com a presença de todos os tutores. A avaliação dos resultados do 
treinamento se dará com a aplicação da avaliação do nível de competência de cada tutor após o treinamento realizado, comparando-a com a realizada anteriormente, assim, pode-se verificar se os mesmos aumentaram o nível da competência deficitária.

Por fim, salienta-se que o T\&D é cada vez mais necessário e permite às organizações desenvolverem o seu capital intelectual, portanto, para o Curso de Graduação em Administração a Distância a criação de um programa de T\&D que alinhe a lacuna existente entre o nível de competência do tutor com o nível desejável para a realização do trabalho, é fundamental para que o tutor alcance seus objetivos.

\section{REFERÊNCIAS}

ARETIO, L. G. Bases conceptuales. In: ARETIO, Lorenzo Garcia. La educación a distancia: de la teoría a la práctica. Barcelona: Ariel, 2002.

BELLONI, M. L. Educação a Distância. Campinas: Editora Autores Associados, 2001. BRANDÃO, H. P.; GUMARÃES, T. de A. Gestão de competências e gestão de desempenho: tecnologias distintas ou instrumentos de um mesmo construto? RAE, São Paulo, v. 41, n. 1, Jan./Mar. 2001.

CHIAVENATO, I. Desempenho humano nas organizações: como desenhar cargos e avaliar o desempenho. São Paulo: Atlas, 2001.

DESSLER, G. Administração de recursos humanos, 2 ed. São Paulo: Prentice Hall, 2003.

DUTRA, J. de S. Gestão de pessoas: modelos, processos, tendências e perspectivas. São Paulo: Atlas, 2004.

EMERENCIANO, M. S. J.; SOUSA, C. A. L.; FREITAS, L. G. Ser presença como Educador, professor e Tutor. In: VIII Congresso Brasileiro de Educação a Distância, 8 de agosto de 2001. Brasilia, DF.

GIL, A. C. Administração de recursos humanos: um enfoque profissional. São Paulo: Atlas, 1994.

GIL, A. C. Como elaborar projetos de pesquisa. 4. ed. São Paulo: Atlas 2007.

HANASHIRO, D. M. M; TEIXEIRA, M. T.; ZACCARELLI, L. M. (org.). Gestão do fator humano: uma visão baseada nos stakeholders. 2.ed. São Paulo: Saraiva, 2008.

LANDIM, C. M. das M. P. F. Educação a distância: algumas considerações. Rio de Janeiro: Cláudia Maria das Mercês Paes Ferreira Landim, 1997.

LEME, R. Aplicação prática de gestão de pessoas por competências: mapeamento, treinamento, seleção, avaliação e mensuração de resultados de treinamento. Rio de Janeiro: Qualitymark, 2005.

MALVESTITI, M. L. Tutoria em cursos pela internet. 2005. Disponível em: < www.abed.org.br/congresso2005 >. Acesso em: 15 Ago. 2007.

MARRAS, J. P. Administração de recursos humanos: do operacional ao estratégico. 3. ed. São Paulo: Futura, 2000.

MORAES, M. de. A monitoria como serviço de apoio ao aluno na educação a distância. Florianópolis, 2004. 229f. Tese (Doutorado) - Universidade Federal de Santa Catarina, Centro Tecnológico. Programa de Pós-Graduação em Engenharia de Produção.

RABAGLIO, M. O. Ferramentas de avaliação com foco em competências. Rio de Janeiro: Qualitymark, 2004.

TACHIZAWA, T.; FERREIRA, V. C. P.; FORTUNA, A. A. M. Gestão com pessoas: uma abordagem aplicada às estratégias de negócios. 5. ed. Rio de Janeiro: FGV, 2006.

TRIVIÑOS, A. N. S. Introdução à pesquisa em ciências sociais: a pesquisa qualitativa em educação. São Paulo: Atlas, 2006. 


\section{APÊNDICE 1}

\begin{tabular}{|c|c|c|c|c|c|c|c|c|c|}
\hline \multicolumn{10}{|c|}{+2} \\
\hline Aval & iado: & & & & \multirow{2}{*}{\multicolumn{5}{|c|}{ Data: __l____-_-_ }} \\
\hline \multicolumn{5}{|c|}{ Avaliador: } & & & & & \\
\hline 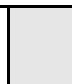 & $\begin{array}{l}\text { Excelente } \\
5\end{array}$ & $\begin{array}{c}\text { Bom } \\
4\end{array}$ & $\begin{array}{l}\text { Médio } \\
3\end{array}$ & $\begin{array}{l}\text { Insatisfatório } \\
2\end{array}$ & \multicolumn{5}{|c|}{$\begin{array}{l}\text { Inaceitável } \\
\quad 1\end{array}$} \\
\hline & $\begin{array}{l}\text { ito forte evidência } \\
\text { do indicador }\end{array}$ & $\begin{array}{l}\text { Boa evidência } \\
\text { do indicador }\end{array}$ & $\begin{array}{l}\text { Alguma evidência } \\
\text { do indicador }\end{array}$ & $\begin{array}{l}\text { Pouca evidência } \\
\text { do indicador }\end{array}$ & \multicolumn{5}{|c|}{$\begin{array}{l}\text { Nenhuma evidência } \\
\text { do indicador }\end{array}$} \\
\hline \multicolumn{5}{|c|}{ LISTA DE VERIFICAÇÃO - COMPETÊNCIAS COMPORTAMENTAIS } & 5 & 4 & 3 & 2 & 1 \\
\hline \multicolumn{10}{|c|}{\begin{tabular}{l|l} 
Arganização e Planejamento: capacidade para determinar o conjunto de procedimentos, ações \\
necessárias para a consecução das atividades de forma organizada, com o intuito de aperfeiçoar os \\
procedimentos e conseguir melhores resultados.
\end{tabular}} \\
\hline 1 & \multicolumn{4}{|c|}{ Cumpre os prazos para correção de provas } & & & & & \\
\hline 2 & \multicolumn{4}{|c|}{ Cumpre os prazos para correção das atividades feitas pelos alunos } & & & & & \\
\hline 3 & \multicolumn{4}{|c|}{ Mantémseus materiais no devido local } & & & & & \\
\hline 4 & \multicolumn{4}{|c|}{ Coloca os gabaritos das atividades na devid a pasta } & & & & & \\
\hline 5 & \multicolumn{4}{|c|}{$\begin{array}{l}\text { Encontra facilmente, quando solicitado, as provas de seus alunos (logo após a } \\
\text { correção) }\end{array}$} & & & & & \\
\hline 6 & \multicolumn{4}{|c|}{ Colabora com a organização da sala de tutoria. } & & & & & \\
\hline \multicolumn{10}{|c|}{ Total de pontos competência A } \\
\hline B & \multicolumn{9}{|c|}{$\begin{array}{l}\text { Pró-atividade: capacidade de oferecer soluções e ideias novas por iniciativa própria, antecipando- } \\
\text { se a possíveis problemas que poderão surgir, disposição para iniciar e manter ações que irão alterar } \\
\text { o ambiente. }\end{array}$} \\
\hline 1 & \multicolumn{4}{|c|}{ Oferece materiais que complementema disciplina } & & & & & \\
\hline 2 & \multicolumn{4}{|c|}{$\begin{array}{l}\text { Encontra falhas no material didático e as comunica antes que os alunos } \\
\text { questionem }\end{array}$} & & & & & \\
\hline 3 & \multicolumn{4}{|c|}{$\begin{array}{l}\text { Identifica pos síveis problemas que poderão surgir emrelação as atividades } \\
\text { propostas }\end{array}$} & & & & & \\
\hline 4 & \multicolumn{4}{|c|}{$\begin{array}{l}\text { Compartilha com os colegas de trabalho os problemas e as soluções encontradas } \\
\text { antes que os colegas encontremos mesmos problemas }\end{array}$} & & & & & \\
\hline 5 & \multicolumn{4}{|c|}{ É ativo, participante, não mero es pectador } & & & & & \\
\hline \multicolumn{10}{|c|}{ Total de pontos competência $B$} \\
\hline $\mathrm{C}$ & \multicolumn{9}{|c|}{$\begin{array}{l}\text { Automotivação: forte impulso } \\
\text { própria, com energia e persist } \\
\text { Tem motivacão nara sertutor }\end{array}$} \\
\hline 1 & Tem motivação $p$ & a sertutor & & & & & & & \\
\hline 2 & \multicolumn{4}{|c|}{ Procura criar sua própria identidade como tutor } & & & & & \\
\hline 3 & \multicolumn{4}{|c|}{ Tem consciência da importância do seu papel como tutor } & & & & & \\
\hline 4 & Aprende comset & erros & & & & & & & \\
\hline 5 & Toma iniciativa $\mathrm{n}$ & realização das t & & & & & & & \\
\hline Tota & I de pontos com & ncia $\mathrm{C}$ & & & & & & & \\
\hline $\mathbf{D}$ & $\begin{array}{l}\text { Capacidade de } \mathrm{s} \\
\text { combinando-as } c\end{array}$ & $\begin{array}{l}\text { ttese e análist } \\
\text { forma a chega }\end{array}$ & $\begin{array}{l}\text { pacidade para aı } \\
\text { ma visão geral e }\end{array}$ & $\begin{array}{l}\text { ar cada parte do } \mathrm{F} \\
\text { is a do todo. }\end{array}$ & & & & & \\
\hline 1 & Envia respostas $\mathrm{s}$ & cintas, porémse & lteraro significado & & & & & & \\
\hline 2 & É objetivo, vaidi & to ao ponto exp & lo a informação de & na clara & & & & & \\
\hline 3 & $\begin{array}{l}\text { Entende as tarefa } \\
\text { curso }\end{array}$ & alizadas e con & ende a importânci & s mesmas para o & & & & & \\
\hline Tota & I de pontos com & ência D & & & & & & & \\
\hline $\mathbf{E}$ & $\begin{array}{l}\text { Empatia: capacic } \\
\text { necessidades alh }\end{array}$ & $\begin{array}{l}\text { de para tratar: } \\
\text { as, tentando id }\end{array}$ & $\begin{array}{l}\text { ssoas de acordo } \\
\text { car-se com a me }\end{array}$ & $\begin{array}{l}\text { suas reações er } \\
\text { sentir o que ela s }\end{array}$ & & & & & \\
\hline 1 & Identifica-se com & grupo de aluno & & & & & & & \\
\hline 2 & Identifica-se com & s colegas de tra & & & & & & & \\
\hline 3 & Identifica-se com & tutor & & & & & & & \\
\hline 4 & Respeita as opini & es dos outros & & & & & & & \\
\hline 5 & Tem habilidade $\mathrm{p}$ & a trabalhar eme & & & & & & & \\
\hline Tot & OS co & & & & & & & & \\
\hline
\end{tabular}


F Equilíbrio emocional: capacidade para manter o bom humor, não sofrendo alterações bruscas devido ao surgimento de situações adversas.

1 Tem humor e dis posição admiráveis e contagiantes todos os dias

2 Fica estres sado/estressada facilmente

3 É atencioso/atenciosa comos alunos do curso

4 É atencioso/atenciosa como os colegas tutores

Total de pontos competência $\mathbf{F}$

Flexibilidade: capacidade para adaptar-se rapidamente a variações na realização ou surgimento de novas atividades; maleabilidade de espírito para se dedicar a vários estudos ou ocupações.

1 Incorpora facilmente e de forma rápida mudanças nas rotinas de trabalho

2 Adapta-se facilmente a novas rotinas de trabalho

3 Consegue realizar vários trabalhos ao mesmo tempo

Total de pontos competência $\mathbf{G}$

Comprometimento e assiduidade: capacidade para estar sempre presente, apegado ao trabalho

H disponibilizando todo o seu potencial em prol do alcance dos objetivos e metas do curso, colaborando, dando suporte, com total dedicação.

1 Tem orgulho em desempenhar as atividades dentro da equipe

2 Dedica-se na realização do trabalho

3 Tem dedicação comas pes soas envolvidas

4 Preocupa-se comos trabalhos dos colegas

5 Dá o máximo de si para realizar o trabalho

5 Propõe-se a ajudar, mes mo se não faz parte do seu trabalho

6 Vai além, não fica preso somente a função

7 Chega no horário previs to para realização de suas atividades

8 Está sempre dis ponível para auxiliar no que for preciso

9 Responde rapidamente aos questionamentos dos alunos

10 Atende ao telefone prontamente

11 Usa o tempo dis ponível para o des envolvimento de atividades pertinentes a EAD

Total de pontos competência $\mathbf{H}$

I Liderança: capacidade para inspirar, fazer com que os outros a trabalhem com insistência, visando realizar tarefas importantes.

1 Estimula os colegas a trazeremnovas ideias

2 É um modelo a ser seguido, através da ação demonstra como os outros podeme

devemagir

3 Inspira os colegas através do entusiasmo pessoal

4 Ajuda os demais colegas a se desenvolver, eliminando obstáculos

5 Seu comportamento influência os dos demais colegas

6 Inspira os alunos a realizarem suas tarefas

7 Conquista a confiança dos colegas

8 Conquista a confiança dos alunos

Total de pontos competência I

J Criatividade: capacidade para sugerir novas maneiras para realização das tarefas, para resolve problemas de maneira inovadora, para maximizar o uso dos recursos disponíveis.

1 Cria estratégias que motivemos alunos

2 Sempre tem uma alternativa para os problemas que aparecemou apresenta sugestões

3 Oferece alternativas para o melhor uso dos recursos dis poníveis

Total de pontos competência $J$

LISTA DE VERIFICAÇÃ̃O - COMPETÊNCIAS TÉCNICAS

\begin{tabular}{|l|l|l|l|l}
\hline & & & & \\
\hline & & & & \\
\hline & & & & \\
\hline & & & & \\
\hline & & & & \\
\hline & & & & \\
\hline & & & & \\
\hline & & & & \\
\hline & & & & \\
\hline & & & & \\
\hline
\end{tabular}

Conhecimento das rotinas de trabalho: conhecimento de como devem ser realizadas as atividades no processo de tutoria.

1 Termina tudo o que começa, nunca deixa uma atividade inacabada

2 Conduza tutoria semproblemas

3 Cumpre os prazos determinados semprejuízo da qualidade

4 Sabe onde encontrar documentos cominformações a respeito dos alunos

5 Sabe para quemencaminhar uma dúvida técnica a res peito do AVEA

Total de pontos competência $L$

V. $9 \mathrm{~N}^{\mathrm{o}}$ 2, dezembro, 2011 


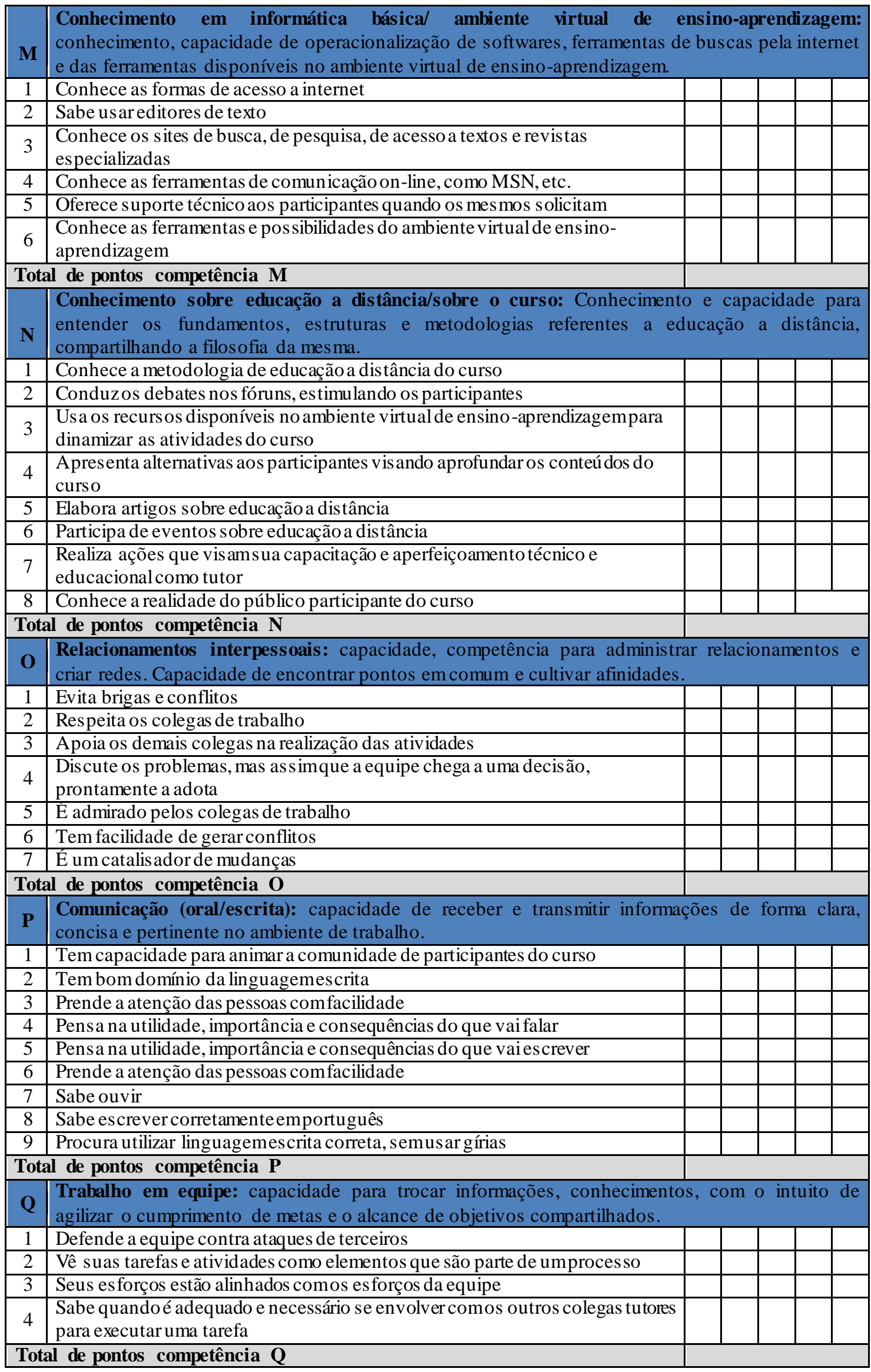

